\title{
AVALIAÇÃO DE PASSIFLORACEAS, FUNGICIDAS E Trichoderma PARA O MANEJO DA PODRIDÃO-DO-COLO DO MARACUJAZEIRO, CAUSADA POR Nectria haematococca ${ }^{1}$
}

\author{
IVAN HERMAN FISCHER ${ }^{2}$, APARECIDA MARQUES DE ALMEIDA ${ }^{3}$, \\ MIRIAN DE SOUZA FILETI ${ }^{4}$, ROSEMARY MARQUES DE ALMEIDA BERTANI ${ }^{5}$, \\ MARIACECÍLIA DE ARRUDA ${ }^{6}$, CÉSAR JÚNIOR BUENO $^{7}$
}

RESUMO - A baixa produtividade do maracujazeiro-amarelo é devida, muitas vezes, a problemas fitossanitários, sendo a Podridão-do-colo, causada por Nectria haematococca, um dos principais problemas na maioria dos Estados produtores do Brasil. O controle desta doença é basicamente preventivo, evitando a introdução do agente patogênico na área. Sendo assim, o presente trabalho teve como objetivos: a) avaliar o comportamento do maracujazeiro-amarelo 'Afruvec', 'IAC 275' e 'Maguary', do tipo pé-franco, e 'Afruvec' enxertado em cinco espécies de Passiflora (P. alata, P. maliformis, P. morifolia, P. mucronata e P. suberosa), em pomar com histórico de Podridão-do-colo; e b) avaliar a eficiência de produtos químicos (oxicloreto de cobre, procloraz e tiabendazol) e biológicos (Trichoderma harzianum e Trichoderma sp.) no controle da Podridão-do-colo em maracujazeiro-amarelo 'Afruvec', sob condições de campo. As espécies P. maliformis, $P$. suberosa e $P$. alata, empregadas como porta-enxerto, apresentaram maior resistência à Podridão-do-colo do maracujazeiro em relação às plantas não enxertadas. Os produtos químicos e biológicos, aplicados em intervalos mensais ou quinzenais no colo da planta $(500 \mathrm{~mL}$ de calda), não foram eficientes no controle da doença.

Termos para indexação: Resistência genética, controle biológico, controle químico, Fusarium, Passiflora.

\section{EVALUATION OF PASSIFLORACEAs, FUNGICIDES AND Trichoderma FOR PASSION FRUIT COLLAR ROT HANDLING, CAUSED BY Nectria haematococca}

\begin{abstract}
The low productivity of yellow passion fruit is often due to the phytosanitary problems, being the Collar rot caused by Nectria haematococca, one of the main problems in the majority of the producing States of Brazil. The disease control is basically preventive, avoiding the introduction of the pathogen in the area. So, the present work aimed at: a) evaluating the behavior of ungrafted yellow passion fruit cultivars 'Afruvec', 'IAC 275' and 'Maguary' passion fruit grafted on five Passiflora species (Passiflora alata, P. maliformis, P. morifolia, P. mucronata and P. suberosa) in an orchard where the disease is frequent; and b) evaluating the efficiency of chemical (copper oxychloride, prochloraz and thiabendazole) and biological products (Trichoderma harzianum and Trichoderma sp.) in the control of the Collar rot in 'Afruvec' yellow passion fruit in field conditions. Yellow passion fruit grafted on P. maliformis, P. suberosa and P. alata presented greater resistance to the Collar rot in relation to the ungrafted yellow passion fruit. The chemical and biological products applied to the base of plants (500 $\mathrm{ml}$ of volume) in monthly or biweekly intervals were not efficient in reducing the disease occurrence.
\end{abstract}

Index terms: Genetic resistance, biological control, chemical control, Fusarium, Passiflora.

\footnotetext{
1'(Trabalho 154-09). Recebido em: 22-06-2009. Aceito para publicação em: 22-02-2010.

${ }^{2}$ Dr. Pesquisador científico da APTA Centro Oeste Bauru, Av. Rodrigues Alves, 40-40, 17030-000, Bauru-SP, E-mail: ihfische@apta.sp.gov.br.

${ }^{3}$ Dra. Pesquisadora científica da APTA Centro Oeste Bauru, E-mail: almeida@apta.sp.gov.br.

${ }^{4}$ Graduanda em Agronomia, Faculdade de Agronomia e Engenharia Florestal de Garça-SP, E-mail: msfileti@hotmail.com.

${ }^{5}$ Dra. Pesquisadora científica da APTA Centro Oeste Bauru, E-mail: rosemary.bertani@apta.sp.gov.br

${ }^{6}$ Dra. Pesquisadora científica da APTA Centro Oeste Bauru, E-mail: mcarruda@apta.sp.gov.br

${ }^{7}$ Dr. Pesquisador científico da APTA Instituto Biológico - Centro Experimental Central, Campinas-SP, E-mail: cjbueno@biologico.sp.gov.br
} 


\section{INTRODUÇÃO}

O Brasil, centro de origem de um grande número de espécies da família Passifloraceae, destacou-se como o maior produtor mundial de maracujá-amarelo (Passiflora edulis f. flavicarpa Deg.), com 664.286 toneladas em 46.866 hectares, em 2007 (IBGE, 2009). A produtividade da cultura pode ser afetada pela ocorrência de doenças, principalmente a Podridão-do-colo, causada por Nectria haematococca Berk \& Br. [F. anamórfica: Fusarium solani (Mart.) Sacc.], a qual mata precocemente as plantas. O patógeno está disperso em todos os Estados brasileiros produtores, sendo responsável por queda da produtividade e constantes migrações da cultura (PONTE et al., 1998).

A Podridão-do-colo do maracujazeiro é observada em plantas adultas, porém sob condições favoráveis, como solos com histórico da doença e elevada temperatura e umidade; as plantas novas também podem sucumbir ao ataque do patógeno (PONTE et al., 1998). O processo inicia-se com o amarelecimento e a perda de turgescência dos brotos, seguida de murcha e seca da planta, resultado do completo anelamento necrótico do colo da planta (COLE et al., 1992). Normalmente, a necrose estende-se acima do nível do solo de 2 a $10 \mathrm{~cm}$, podendo progredir ao longo das raízes (FISCHER; RESENDE, 2008).

O controle da Podridão-do-colo do maracujazeiro deve ser preventivo, não havendo até o momento métodos curativos eficientes, após constatada a doença no pomar. Recomenda-se evitar áreas com histórico da doença, evitar o plantio em solos pesados e compactados, utilizar mudas sadias, evitar ferimentos no colo e no sistema radicular das plantas e erradicar as plantas doentes, visando a reduzir a fonte de inóculo (FISCHER; RESENDE, 2008).

Estudos preliminares, realizados no Pará, com aplicações de benomyl a 500 ppm e captan a 1.500 ppm, contribuíram para prevenir o avanço das infecções de $N$. haematococca em mudas de maracujazeiro inoculadas (NUNES; ALBUQUERQUE, 1995). Banhando o colo da planta com oxicloreto de cobre (60 g/20 L de água), em intervalos bissemanais, durante um ano, Ssekyewa et al. (1999) obtiveram redução de $65 \%$ na incidência da doença em Uganda. Ponte (1993) obteve controle de 75\% com a aplicação de $5 \mathrm{~kg}$ de esterco bovino nas covas. Todavia, isto foi verificado em solo onde espécies de Trichoderma estavam presentes, ao contrário do que Ponte et al. (1998) verificaram com a aplicação de esterco bovino em solo sem a presença de Trichoderma. Sabe-se que a matéria orgânica estimula o crescimento populacional de Trichoderma, fungo reconhecido entre os principais antagonistas de espécies do gênero Fusarium (ETHUR et al., 2007). Inibição in vitro de isolados de $F$. solani por quatro espécies de Trichoderma evidenciou o seu uso potencial no controle da Podridão-do-colo do maracujazeiro (VAZ et al., 2008). No Brasil, existem produtos à base de Trichoderma spp. disponíveis no mercado, embora não sejam registrados devido à ausência de legislação específica para tal. O sucesso do uso de Trichoderma tem sido documentado para patógenos de solo, como Rhizoctonia solani Kühn, Sclerotium rolfsii Sacc., Sclerotinia sclerotiorum (Lib.) de Bary, Fusarium spp. e Pythium spp. (Corabi-Adell, 2004).

Em estudos de resistência a $N$. haematococca, Delanoë (1991) relatou a ocorrência em Passiflora candida Mast. e P. fuchsiiflora Hemsl., enquanto $P$. coccinea Aubl., P. laurifolia L. e P. glandulosa Cav. foram parcialmente resistentes. Algumas linhagens de $P$. edulis f. flavicarpa apresentaram-se resistentes ao patógeno quando comparadas a $P$. edulis f. edulis Sims (LIN; CHANG, 1985). Segundo Ssekyewa et al. (1999), tanto P. edulis f. flavicarpa quanto P. maliformis L. são parcialmente resistentes ao patógeno e podem ser recomendados para uso como porta-enxerto em P. edulis f. edulis e híbridos suscetíveis. Cole et al. (1992) relataram a resistência de $P$. caerulea $\mathrm{L}$. a $N$. haematococca em maracujazeiro. No Brasil, resultados promissores no controle da Podridão-docolo foram obtidos por Cavichioli (2008), com a utilização de $P$. giberti N. E. Brown e $P$. alata Dryander como porta-enxerto para $P$. edulis f. flavicarpa. Em condições de casa de vegetação, Fischer et al. (2005) obtiveram controle da doença com fungicidas em tratamento erradicante e com algumas passifloras distintas do maracujazeiro-amarelo, porém a real eficácia destes tratamentos depende de estudos em condições de campo.

O presente projeto teve como objetivos: a) avaliar o comportamento de maracujazeiros amarelo 'Afruvec', 'IAC 275' e 'Maguary', do tipo pé-franco, e 'Afruvec' enxertado em cinco espécies diferentes de Passiflora spp., em pomar com histórico de Podridão-do-colo; e b) avaliar a eficiência de produtos químicos e biológicos no controle da Podridãodo-colo em maracujazeiro-amarelo 'Afruvec', sob condições de campo.

\section{MATERIAL E MÉTODOS}

Os experimentos foram realizados entre os anos de 2006 e 2009, em dois pomares de maracujazeiro-amarelo com histórico da Podridão-do-colo, localizados em Bauru e Pederneiras-SP. O fungo 
Nectria haematococca, agente causal da doença, foi identificado nos dois pomares, e sua patogenicidade, confirmada em mudas de maracujazeiro 'Afruvec', segundo metodologia de Fischer et al. (2005). O solo dos pomares é do tipo Latossolo Roxo e o terreno levemente inclinado. O clima da região, segundo classificação de Köeppen, é do tipo Aw, tropical chuvoso com inverno seco.

As sementes do maracujazeiro-amarelo e das espécies do gênero Passiflora foram obtidas junto ao Instituto Agronômico de Campinas (IAC) e ao Departamento de Genética da ESALQ/USP. As mudas foram produzidas em casa de vegetação, por meio da semeadura direta em vasos de $2 \mathrm{~L}$, contendo substrato autoclavado composto de terra, esterco bovino e areia $(2: 1: 1)$. As mudas foram transplantas para os pomares com dois meses de idade. As enxertadas foram transplantadas com três meses. A enxertia adotada foi a do tipo "inglês simples". O preparo das covas, adubações, capina, condução das plantas em espaldeiras verticais e tratamentos fitossanitários foram efetuados de acordo com Ruggiero et al. (1996), sem irrigação e com espaçamento de $2,5 \mathrm{~m}$ entre plantas e de 3,0 m entre fileiras.

Reação de porta-enxertos de Passiflora spp. Plantas de maracujazeiro-amarelo 'Afruvec', 'IAC 275' e 'Maguary', do tipo pé-franco, e maracujazeiro-amarelo 'Afruvec' enxertado em cinco espécies de Passiflora spp. (P. morifolia Mast., P. mucronata Lam., P. alata, P. maliformis e P. subero$s a$ L.) foram transplantadas, em novembro de 2006 , para uma área com histórico da Podridão-do-colo, em Bauru-SP. O delineamento experimental utilizado foi de blocos casualizados, com oito tratamentos e dez repetições, sendo cada parcela representada por uma planta.

A incidência de plantas murchas ou mortas decorrentes da doença foi avaliada mensalmente, durante 14 meses, através dos sintomas visuais e isolamento do patógeno em meio de cultura (FISCHER et al., 2005). Após a obtenção dos dados de incidência, calculou-se a área abaixo da curva de progresso da doença (AACPD), conforme Campbell e Madden (1990). Comparou-se a incidência da doença entre os tratamentos por meio de teste não paramétrico de comparação de múltiplas proporções, ao nível de 5\% de probabilidade, conforme descrito por Zar (1999).

Dados de temperatura média mensal e precipitação acumulada, em 2007, obtidos na estação meteorológica automática IPMet de Bauru-SP, foram correlacionados $(P>0,05)$ com os dados de incidência média da Podridão-do-colo do maracujazeiro.

\section{Tratamento químico e biológico}

Plantas de maracujazeiro-amarelo 'Afruvec' de tipo pé-franco foram transplantadas para dois pomares com histórico da Podridão-do-colo, sendo um em setembro (Pederneiras- SP) e outro em novembro de 2006 (Bauru-SP). Os tratamentos foram os mesmos nos dois pomares e consistiram em regas mensais no colo da planta, a partir do transplantio, com $500 \mathrm{~mL}$ de oxicloreto de cobre $(0,04$ e $0,2 \%)$, procloraz $(0,02$ e $0,1 \%)$, tiabendazol $(0,02$ e $0,1 \%)$, Trichoderma harzianum Rifai (Ecotrich $\left.{ }^{\circledR}\right)\left(10^{7}\right.$ ufc. $\mathrm{mL}^{-1}$ ) e o controle (água).

Em outro ensaio instalado nos mesmos pomares, em outubro de 2007 , foram testados os seguintes produtos: oxicloreto de cobre $(0,1 \%)$, procloraz $(0,05 \%)$, tiabendazol $(0,05 \%)$, Trichoder-

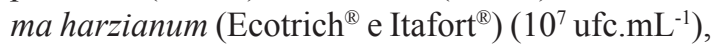
Trichoderma sp. $\left(\right.$ Agrotrich $^{\circledR}$ e Tricho Plantio $\left.{ }^{\circledR}\right)\left(10^{7}\right.$ ufc. $\mathrm{mL}^{-1}$ ) e o controle (água). A aplicação dos tratamentos foi realizada por meio de regas $(500 \mathrm{~mL})$ quinzenais. Para o preparo do inóculo de Trichoderma harzianum e Trichoderma sp., realizaram-se o crescimento e a esporulação dos mesmos por sete dias, em meio de cultura batata-dextrose-ágar, e a concentração da suspensão de conídios foi ajustada em hemacitômetro. Em adição aos tratamentos com aplicação mensal e quinzenal do antagonista Trichoderma, realizou-se um tratamento preventivo, com 15 dias de antecedência ao transplante, das covas e das mudas, com Trichoderma harzianum e Trichoderma sp..

Para os quatro ensaios, adotou-se o delineamento experimental em blocos casualizados, com 10 repetições (plantas) para cada tratamento. A condução das plantas e os tratos culturais, assim como a avaliação dos dados de incidência da Podridão-docolo do maracujazeiro foram os mesmos descritos anteriormente.

\section{RESULTADOS E DISCUSSÃO}

\section{Reação de porta-enxertos de Passiflora \\ spp. \\ Os sintomas da Podridão-do-colo do mara- cujazeiro apareceram aos dois meses após o trans- plantio (Figura 1), concordando com Roncatto et al. (2004), em áreas com histórico da doença. Com base nos resultados de AACPD (P. maliformis - 39,5; $P$. suberosa - 41,5; P. alata - 60,0; 'IAC 275'-82,5; 'Maguary' - 83,5; P. mucronata - 88,5, 'Afruvec' - 99,0 e P. morifolia - 118), menores incidências da doença foram observadas nas plantas enxertadas em P. maliformis, $P$. suberosa e $P$. alata, que foram significativamente inferiores a P. mucronata, P. mo-}


rifolia e 'Afruvec' pé-franco. Maracujazeiro-amarelo 'IAC 275' e 'Maguary' foram estatisticamente semelhantes a 'Afruvec' pé-franco e enxertado em P. alata (Figura 2). Esta maior suscetibilidade do maracujazeiro-amarelo 'Afruvec' em relação às demais espécies estudadas havia sido relatada em condições de vaso, em casa de vegetação, por Fischer et al. (2005).

Embora Fischer et al. (2005) constatassem em casa de vegetação que $P$. morifolia se comportou melhor que $P$. edulis f. flavicarpa, na presente pesquisa, obtiveram-se $100 \%$ de mortalidade aos três meses após o transplante, evidenciando a incompatibilidade desta espécie como porta-enxerto para $P$. edulis f. flavicarpa 'Afruvec'. Segundo Chaves et al. (2004) e Nogueira Filho et al. (2005), problemas de incompatibilidade da copa com o porta-enxerto e de baixa taxa de germinação de algumas espécies silvestres podem ser resolvidos com o uso de portaenxertos provenientes do enraizamento de estacas herbácias das passifloras silvestres ou pela técnica da enxertia hipocotiledonar.

A resistência parcial de $P$. edulis f. flavicarpa e $P$. maliformis a $N$. haematococca, relatada por Ssekyewa et al. (1999), foi comprovada apenas para a segunda espécie. Melhor comportamento de $P$. alata em relação a $P$. edulis f. flavicarpa também foi observado por São José et al. (2000) e Cavichioli (2008), em local com histórico da doença. Porém, Maldonado (1991) verificou suscetibilidade em $P$. alata. A suscetibilidade desta espécie a nematoides de galhas (MENEZES, 1994) pode estar relacionada à porta de entrada à infecção por Fusarium (VIANA et al., 2003). A doença é conhecida por interagir com a podridão-do-pé do maracujazeiro, causada por Phytophthora spp., nematoides, e ataque de formigas e cupins (LIN;CHANG, 1985; CEDEÑO et al., 1990). Lin e Chang (1985), Cedeño et al. (1990) e Fischer et al. (2005) só reproduziram os sintomas da doença quando foram realizados ferimentos no colo ou nas raízes das plantas, previamente à inoculação, sendo o desenvolvimento da podridão sempre maior nas plantas com ferimentos (PLOETZ, 1991).

Com base nos resultados obtidos e segundo Braga et al. (2006) e Fischer e Rezende (2008), o uso de porta-enxerto resistente constitui-se, a curto prazo, na melhor forma de convivência com o problema em locais contaminados. Passiflora caerulea L., espécie empregada como porta-enxerto para $P$. edulis f. edulis, na África do Sul, mostra-se resistente a F. solani, F. oxysporum f. sp. passiflorae Purss e Phytophthora nicotianae Breda de Haan (GRECH; RIJKENBERG, 1991; COLE et al., 1992). Na escolha do porta-enxerto, além da resistência às doenças, devem-se considerar a compatibilidade da enxertia e a produtividade. Em função do número reduzido de plantas sobreviventes em alguns tratamentos, não foi feita comparação de produção entre eles. Yamashiro e Landgraff (1979) indicaram P. alata como um promissor porta-enxerto, pois além de ser resistente à doença, confere à copa maior precocidade e manutenção da qualidade dos frutos, permitindo também o uso de solos mais úmidos, os quais favorecem o patógeno. Lin e Chang (1985) encontraram algumas linhagens de $P$. edulis f. flavicarpa resistentes ao patógeno, indicando a possibilidade de o melhoramento genético intraespecífico ser mais promissor, principalmente pelos aspectos favoráveis de compatibilidade e produtividade da espécie.

Observou-se correlação significativa $(\mathrm{r}=0,62$; $P>0,05)$ entre a incidência da doença (plantas mortas) (Figura 1) e a temperatura média mensal (Figura 3) entre os meses de fevereiro a dezembro de 2007 . Neste ano, a temperatura média mínima foi de $18,5^{\circ} \mathrm{C}$, e a máxima foi de $25,6^{\circ} \mathrm{C}$ (IPMET-Bauru, 2009). Luthemah e Musaphur (1993) observaram que a incidência da doença é favorecida por temperatura e umidade elevadas. Em condições in vitro, maior crescimento do patógeno ocorre entre 25 e $30^{\circ} \mathrm{C}$ (SSEKYEWA et al., 1999).

Com relação à precipitação, a correlação embora positiva $(r=0,50)$ não foi significativa. Em 2007, a precipitação média acumulada no ano foi de 112,24 mm. Vale ressaltar que, no mês de julho desse ano, houve uma precipitação acumulada de $240 \mathrm{~mm}$, atípica para esse mês (Figura 2) (IPMET-Bauru, 2009).

\section{Tratamento químico e biológico}

Nos quatro experimentos em que foram avaliados os fungicidas oxicloreto de cobre, procloraz e tiabendazol e os agentes de controle biológico Trichoderma harzianum e Trichoderma sp., aplicados em intervalos mensais e quinzenais, não foram observadas reduções significativas na incidência da Podridão-do-colo do maracujazeiro, em comparação ao tratamento-controle (água) (Tabela 1). Sendo, inclusive, observado aumento na incidência (AACPD) quando aplicado procloraz a $0,1 \%(54,5)$ em relação ao tratamento-controle $(30,5)$, no pomar de Bauru. Estes resultados divergem dos $65 \%$ de controle obtidos por Ssekyewa et al. (1999), com oxicloreto de cobre em Uganda.

O sucesso do tratamento químico no controle da Podridão-do-colo em plantas envasadas, obtido por Fischer et al. (2005) em solo previamente infestado, deve-se, possivelmente, às condições controladas (temperatura e umidade do solo) da casa de vegetação, uma vez que in vitro os fungicidas se mostra- 
ram também eficientes no controle do patógeno. Já em condições de campo e em terrenos em declive, como neste trabalho, a disseminação e o potencial de inóculo do patógeno no solo, o tipo de solo e as condições ambientais devem ter sido muito favoráveis ao desenvolvimento da doença, não permitindo uma proteção eficaz da planta com os fungicidas e com os produtos biológicos. Segundo Fischer e Rezende (2008), o fungo sobrevive no solo durante anos na forma de estruturas de resistência (clamidósporos), podendo ser dispersos por meio de qualquer prática em que haja movimento do solo infestado. De maneira geral, a mortalidade de plantas foi menor nos meses de inverno de 2007 e 2008, entretanto correlações $(P>0,05)$ entre a incidência de plantas mortas e os dados de temperatura média e precipitação acumulada mensal não foram observadas (dados não apresentados).

Antagonismo in vitro pela metodologia de pareamento (MARIANO, 1993) foi observado entre isolados de Trichoderma harzianum (Ecotrich $\left.{ }^{\circledR}\right)$ e Trichoderma sp. (Tricho Plantio ${ }^{\circledR}$ ) em relação a um isolado de $N$. haematococca, obtido de planta doente do pomar de Pederneiras, e entre isolados de Trichoderma harzianum (Itafort ${ }^{\circledR}$ ) e Trichoderma sp. (Agro-
$\operatorname{trich}^{\circledR}$ ) em relação ao isolado de $N$. haematococca obtido do pomar de Bauru (dados não apresentados). Entretanto, assim como observado para os fungicidas in vitro e em casa de vegetação (FISCHER et al., 2005), os resultados obtidos no presente trabalho com Trichoderma spp. foram insatisfatórios. Isto deve-se, provavelmente, ao não estabelecimento deste antagonista no solo, possivelmente devido à influência de fatores ambientais e de solo, difíceis de serem mensurados.

Produtos biológicos são constituídos de organismos vivos e devem sobreviver, colonizar e multiplicar-se na planta ou no ambiente onde são aplicados, a fim de se obterem os resultados esperados. Assim, a eficiência dos bioprodutos pode ser afetada diretamente pelos fatores bióticos locais (organismos vivos presentes) e abióticos (tipo de solo, umidade, $\mathrm{pH}$ e temperatura), pois são produtos bem mais sensíveis e específicos quando comparados aos produtos químicos. Contudo, considerando que isolados de Trichoderma com capacidade antagonista geralmente são isolados de solo rizosférico devido à habilidade em habitar esse ambiente (COOK, 1993), recomenda-se a busca de outros antagonistas na rizosfera de plantas sobreviventes nos pomares com histórico da Podridão-do-colo do maracujazeiro.

TABELA 1 - Valores da área abaixo da curva de progresso da incidência (AACPD) da Podridão-do-colo em pomares de maracujazeiro-amarelo 'Afruvec' de Bauru e Pederneiras-SP, tratados com produtos químicos e biológicos, em intervalos quinzenais ou mensais.

\begin{tabular}{|c|c|c|}
\hline \multirow{2}{*}{$\begin{array}{l}\text { Tratamentos } \\
\text { (Aplicações mensais) }\end{array}$} & \multicolumn{2}{|c|}{ AACPD } \\
\hline & Pederneiras-SP (11/2006-04/2007) & Bauru-SP $(12 / 2006-03 / 2008)$ \\
\hline Oxicloreto de $\mathrm{Cu} 0,04 \%$ & $23,5 \mathrm{a}^{1}$ & $28,0 \mathrm{a}$ \\
\hline Oxicloreto de $\mathrm{Cu} 0,2 \%$ & $29,0 \mathrm{a}$ & $53,5 \mathrm{bc}$ \\
\hline Procloraz $0,02 \%$ & $22,0 \mathrm{a}$ & $25,5 \mathrm{a}$ \\
\hline Procloraz $0,1 \%$ & $24,0 \mathrm{a}$ & $54,5 \mathrm{c}$ \\
\hline Tiabendazol $0,02 \%$ & $22,0 \mathrm{a}$ & $32,0 \mathrm{abc}$ \\
\hline Tiabendazol 0,1\% & $24,5 \mathrm{a}$ & $33,5 \mathrm{abc}$ \\
\hline Trichoderma harzianum $\left(\right.$ Ecotrich $\left.^{\circledR}\right)$ & $21,5 \mathrm{a}$ & $46,5 \mathrm{abc}$ \\
\hline Controle & $24,5 \mathrm{a}$ & $30,5 \mathrm{ab}$ \\
\hline (Aplicações quinzenais) & Pederneiras-SP (11/2006-04/2007) & Bauru-SP (11/2007-04/2008) \\
\hline Oxicloreto de $\mathrm{Cu} 0,1 \%$ & $64,5 \mathrm{ab}$ & $28,0 \mathrm{a}$ \\
\hline Tiabendazol 0,05\% & $72,0 \mathrm{ab}$ & $23,5 \mathrm{a}$ \\
\hline Procloraz $0,05 \%$ & $81,0 \mathrm{~b}$ & $24,5 \mathrm{a}$ \\
\hline Trichoderma harzianum $\left(\right.$ Itafort $\left.^{\mathbb{B}}\right)$ & $66,0 \mathrm{ab}$ & $25,0 \mathrm{a}$ \\
\hline Trichoderma harzianum $\left(\right.$ Ecotrich $\left.^{\circledR}\right)$ & $49,0 \mathrm{a}$ & $23,5 \mathrm{a}$ \\
\hline Trichoderma sp. (Tricho Plantio ${ }^{\circledR}$ ) & $79,0 \mathrm{~b}$ & $25,0 \mathrm{a}$ \\
\hline Trichoderma sp. $\left(\right.$ Agrotrich $^{\circledR}$ ) & $59,5 \mathrm{ab}$ & $22,5 \mathrm{a}$ \\
\hline Controle & $57,5 \mathrm{ab}$ & $21,5 \mathrm{a}$ \\
\hline
\end{tabular}

${ }^{1}$ Dados seguidos pela mesma letra na coluna não diferem entre si, ao nível de 5\% de probabilidade (Zar, 1999). 


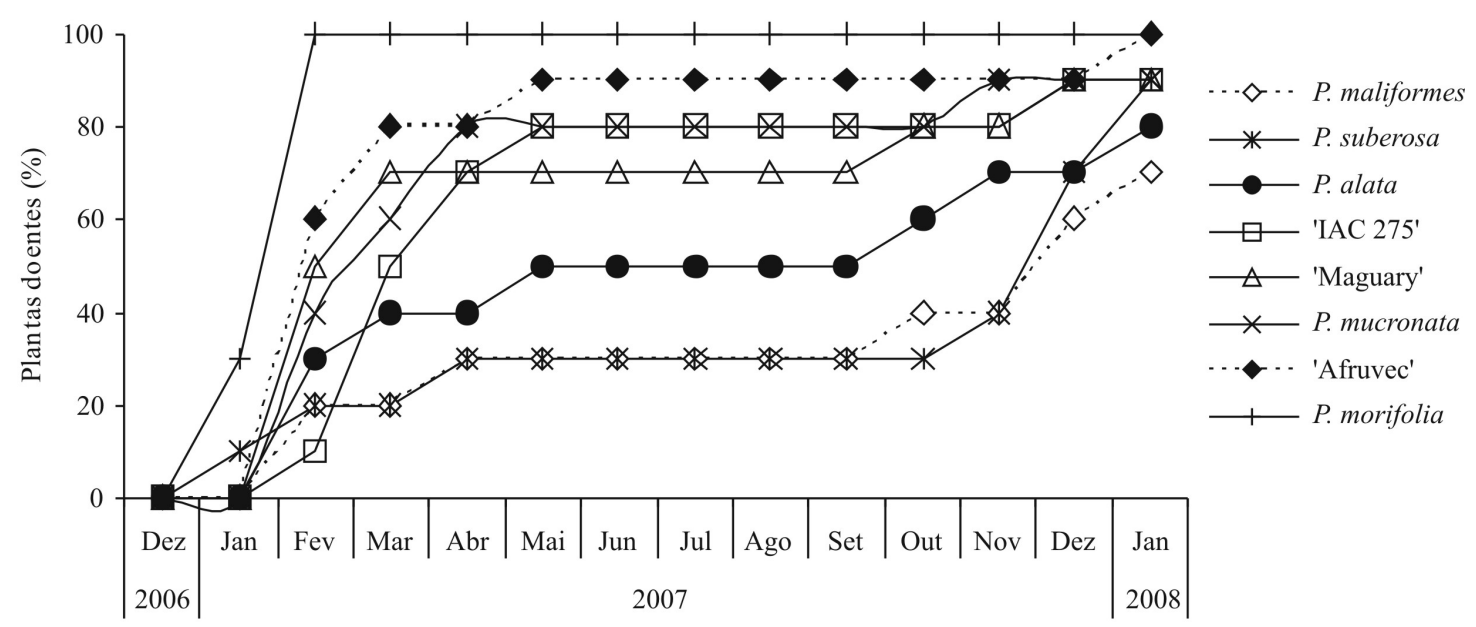

Meses/Anos

FIGURA 1 - Incidência (\%) da Podridão-do-colo, causada por Nectria haematococca, em maracujazeirosamarelo 'Afruvec', 'IAC 275' e 'Maguary', do tipo pé-franco, e em maracujazeiro-amarelo 'Afruvec' enxertado em cinco espécies de Passiflora (P. morifolia, P. mucronata, P. alata, P. maliformis e P. suberosa), em pomar de Bauru-SP (2007/08).

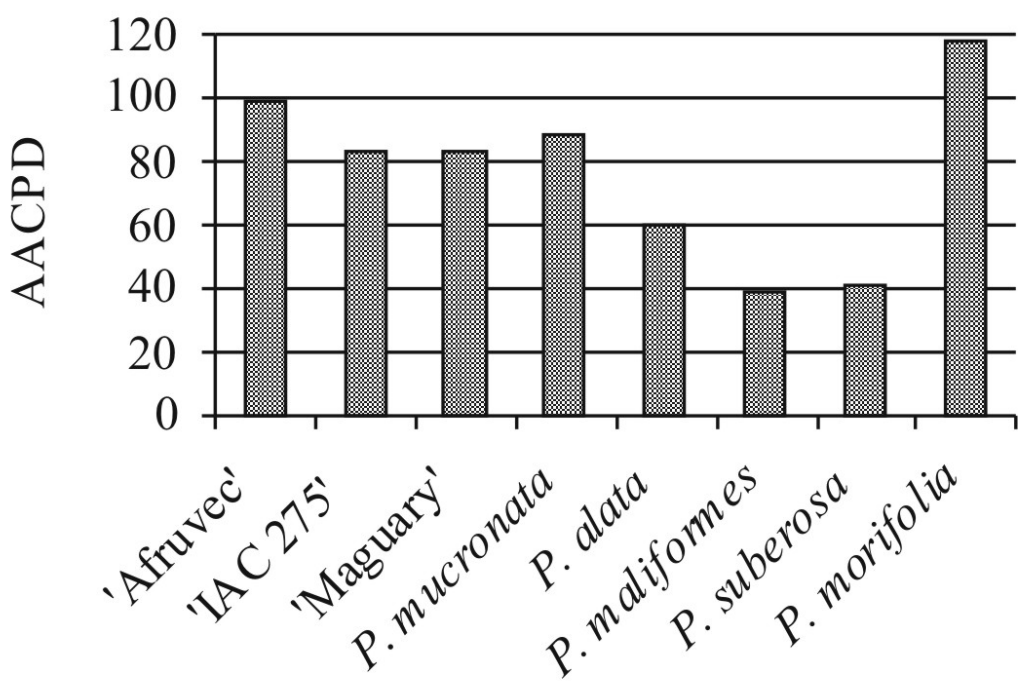

Cultivar/espécie de maracujazeiro

FIGURA 2 - Área abaixo da curva de progresso da incidência (AACPD) da Podridão-do-colo, em maracujazeiros-amarelo 'Afruvec', 'IAC 275' e 'Maguary', do tipo pé-franco, e em maracujazeiroamarelo 'Afruvec' enxertado em cinco espécies de Passiflora (P. morifolia, P. mucronata, $P$. alata, P. maliformis e P. suberosa), em pomar de Bauru-SP (2007/08). 


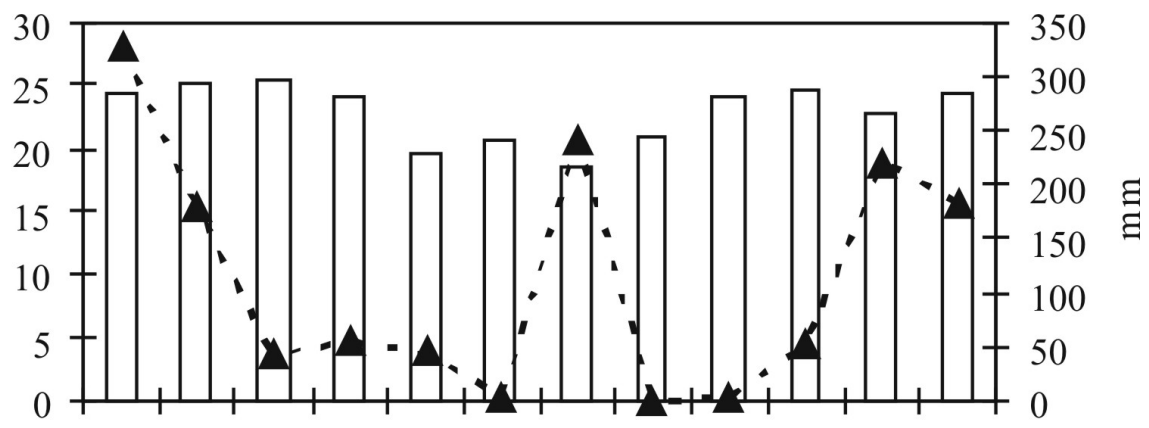

Jan Fev Mar Abr Mai Jun Jul Ago Set Out Nov Dez

Meses - 2007

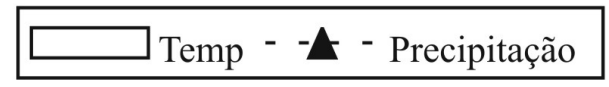

FIGURA 3 - Temperatura média mensal $\left({ }^{\circ} \mathrm{C}\right)$ e precipitação acumulada $(\mathrm{mm})$ na estação meteorológica automática IPMet de Bauru-SP, em 2007 (IPMET-Bauru, 2009).

\section{CONCLUSÕES}

1- As espécies Passiflora maliformis, $P$. suberosa e $P$. alata, utilizadas como porta-enxerto para $P$. edulis f. flavicarpa, demonstram maior resistência à Podridão-do-colo em relação às plantas de maracujazeiro-amarelo não enxertadas.

2- Os fungicidas oxicloreto de cobre, procloraz e tiabendazol e os agentes de controle biológico Trichoderma harzianum e Trichoderma sp. não são eficientes no controle da Podridão-do-colo do maracujazeiro em pomares com histórico da doença.

\section{REFERÊNCIAS}

BRAGA, M.F.; SANTOS, E.C. dos; JUNQUEIRA, N.T.V.; SOUSA, A.A.T.C de; FALEIRO, F.G.; REZENDE, L.N.; JUNQUEIRA, K.P. Enraizamento de estacas de três espécies silvestres de Passiflora. Revista Brasileira de Fruticultura, Jaboticabal, v.28, n.2, p.284-288, 2006.

CAMPBELL, C.D.; MADDEN, L.V. Introduction to plant disease epidemiology. New York: John Willey, 1990. 532p.

CAVICHIOLI, J.C. Enxertia hipocotiledonar e convencional de maracujazeiro-amarelo sobre três porta-enxertos. 2008. 91 f. Tese (Doutorado em Agronomia) - Faculdade de Engenharia, Universidade Estadual Paulista, Ilha Solteira, 2008.
CEDEÑO, L.; PALACIOS-PRU, E.; MARQUES, N.J.; TAVIRA, M.E. Nectria haematococca, agente causal de la muerte repentina de la parchita em Venezuela. Fitopatología Venezolana, Maracay, v.3, n.1, p.15-18, 1990.

CHAVES, R.C.; JUNQUEIRA, N.T.V.; MANICA, I.; PEIXOTO, J.R.; PEREIRA, A.V.; FIALHO, J.F. Enxertia de maracujazeiro-azedo em estacas herbáceas enraizadas de espécies de passifloras nativas. Revista Brasileira de Fruticultura, Jaboticabal, v.26, n.1, p.120-123, 2004.

COLE, D.L.; HEDGES, R.; NDOWORA, T. A wilt of passion fruit (Passiflora edulis f. edulis Sims) caused by Fusarium solani and Phytophthora nicotianae var. nicotianae. Tropical Pest Management, London, v.38, n.4, p.362-366, 1992.

COOK, R.J. Making greater use of introduced microorganisms for biological control of plant pathogen. Annual Review of Phytopathology, Saint Paul, v.31, n.1, p.53-80, 1993.

CORABI-ADELL, C. Biodiversidade do gênero Trichoderma (HYPOCREALES-FUNGI) mediante técnicas moleculares e análise ecofisiográfica. 2004. 220 f. Tese (Doutorado em Ciências Biológicas) - Universidade Estadual Paulista, Rio Claro, 2004. 
DELANOË, O. Etude de la résistance de passiflores de Guyane française vis-à-vis de Fusarium pathogènes de la culture des fruits de la Passion (Passiflora edulis f. flavicarpa). Fruits, Montpellier, v.46, p.593-600, 1991

ETHUR, L.Z.; BLUME, E.; MUNIZ, F.B.; FLORESI, M.G.V. Seleção de antagonistas fúngicos a Fusarium solani e Fusarium oxysporum em substrato comercial para mudas. Ciência Rural, Santa Maria, v.37, n.6, p.1794-1797, 2007.

FISCHER, I.H.; LOURENCO, S.A.; MARTINS, M.C.; KIMATI, H.; AMORIM, L. Seleção de plantas resistentes e de fungicidas para o controle da podridão do colo do maracujazeiro causada por Nectria haematococca. Fitopatologia Brasileira, Lavras, v.30, n.3, p.250-258, 2005.

FISCHER, I. H. ; RESENDE, J. A. M. Diseases of Passion Flower (Passiflora spp.). Pest Technology, Kagawa, v.2, n.1, p.1-19, 2008.

GRECH, N.M.; RIJKENBERG, F.H.J. Laboratory and field evaluation of the performance of Passiflora caerulia as a rootstock tolerant to certain fungal pathogens. Journal of Horticultural Science, Littlehampton, v.66, n.6, p.725-729, 1991.

IBGE. Sistema IBGE de recuperação automática SIDRA, 2007. Maracujá. Brasília: Ministério do Planejamento, Orçamento e Gestão, 2009. Disponível em: $<$ http://www.sidra.ibge.gov.br $>$. Acesso em: 03 jun. 2009.

IPMET - Instituto de Pesquisas Meteorológicas. Estação Meteorológica Automática. Bauru: UNESP, 2009. Disponível em: <http://web.ipmet.unesp.br/ index 2.php?menu_esq1=\&abre=ipmet html/estacao/historico.php>. Acesso em: 03 jun. 2009.

LIN, Y.S.; CHANG, H.J. Collar rot of passion fruit possibly caused by Nectria haematococca in Taiwan. In: PARKER, C.A.; ROVIRA, A.D.; MOORE, K.J.; ONG, P.T.W.; KOLLMORGEN, J.F. (Ed.). Ecology and management of soilborne plant pathogens. St. Paul: APS Press, 1985. p.41-45.

LUTCHMEAH, R.S.; MUSAPHUR, F.B. Sudden wilt of yellow passion fruit (Passiflora edulis $\mathrm{f}$. flavicarpa) caused by Fusarium solani in Mauritius. FAO Plant Protection Bulletin, Reduit, v.41, n.2, p.126-127, 1993.
MALDONADO, J.F.M. Utilização de porta-enxertos do gênero Passiflora para maracujazeiro-amarelo (Passiflora edulis Sims f. flavicarpa Deg.). Revista Brasileira de Fruticultura, Jaboticabal, v.13, n.2, p.51-54, 1991.

MARIANO, R.L.R. Métodos de seleção "in vitro" para controle microbiológico. Revisão Anual de Patologia de Plantas, Passo Fundo, v.1, p.369-409, 1993.

MENEZES, J. M. T.; OLIVEIRA, J. C.; RUGGIERO, C.; BANZATTO, D. A. Avaliação da taxa de pegamento de enxertos de maracujá-amarelo sobre espécies tolerantes à "morte prematura de plantas". Científica, Jaboticabal, v.22, n.1, p.95-104, 1994.

NOGUEIRA FILHO, G.C.; RONCATTO, G.; RUGGIERO, F.C.; MALHEIROS, E.B. Propagação vegetativa do maracujazeiro-conquista de novas adesões. In: FALEIRO, F.G.; JUNQUEIRA, N.T.V.; BRAGA, M.F. (Ed.). Maracujá: germoplasma e melhoramento genético. Planaltina-DF: Embrapa Cerrados, 2005. p.341-356.

NUNES, A.M.L.; ALBUQUERQUE, F.C. Podridãodo-coleto do maracujazeiro (Passiflora edulis). Fitopatologia Brasileira, Brasília, v.20, p.356, 1995.

PLOETZ, R.C. Sudden wilt of passionfruit in southern Florida caused by Nectria Haematococca. Plant Disease, Saint Paul, v.75, n.10, p.1071-1073, 1991.

PONTE, J.J. da. As doenças do maracujá-amarelo no Nordeste do Brasil. Revista Brasileira de Fruticultura, Jaboticabal, v.15, n.1, p.11-14, 1993.

PONTE, J.J. da; FRANCO, A.; AGUIÁR DE HOLANDA, Y.C.; SILVEIRA FILHO, J. Calagem, adubação orgânica e fungicida de solo no controle da podridão-do-pé (Fusarium solani) do maracujáamarelo. Fitopatología Venezolana, Maracay, v.12, n.1, p.30-31. 1998.

RONCATTO, G.; OLIVEIRA, J.C.; RUGGIERO, C.; NOGUEIRA FILHO, G.C.; CENTURION, M.A.P.C.; FERREIRA, F.R. Comportamento de maracujazeiros (Passiflora spp.) quanto à morte prematura. Revista Brasileira de Fruticultura, Jaboticabal, v.26, n.3, p.552-554, 2004. 
RUGGIERO, C.; SÃO JOSE, A.R.; VOLPE, C.A.; OLIVEIRA, J.C.; DURIGAN, J.F.; BAUMGARTNER, J.G.; DA SILVA, J.R.; NAKAMURA, K.I.; FERREIRA, M.E.; KAVATI, R.; PEREIRA, V.P. Maracujá para exportação: aspectos técnicos da produção. Brasília: EMBRAPA, SPI, 1996. 64p. (Série Publicações Técnicas FRUPEX, 19).

SÃO JOSÉ, A.R.; SANTOS, A.; SILVA, A.C. da; BOMFIM, M.P.; MORAIS, O.M.; ATAIIDE, E.M.; BARBOSA, N.M.L. Fusariose no semiárido. In: CONGRESSO BRASILEIRO DE FRUTICULTURA, 16., 2000, Fortaleza. Anais... p.470.

SILVA, K.S.; REBOUÇAS, T.N.H.; BOMFIM, M.P.; SILVA, D.S.; SÃO JOSÉ, A.R.; BENETT, C.G.S. Atividade antagônica in vitro de isolados de Trichoderma spp. ao fungo Phytophthora citrophthora. Semina: Ciências Agrárias, Londrina, v.29, n.4, p.749-754, 2008.

SSEKYEWA, C.; FINA OPIO, A.; SWINBURNE, T.R.; VAN DAMME, P.L.V.; ABUBAKAR, Z.M. Sustainable management of collar rot disease of passion fruits in Uganda. International Journal of Pest Management, London, v.45, n.3, p.173-177, 1999.
VAZ, A.B.; SÃO JOSÉ, A.R.; SANTOS, A.; NOVAES, Q.S. Potencial uso de Trichoderma spp. para o biocontrole de Fusarium solani em maracujazeiro. Tropical Plant Pathology, Lavras, v.33, p.142, 2008.

VIANA, F.N.P.; FREIRE, F.C.O.; CARDOSO, J.E.; VIDAL, J.C. Principais doenças do maracujazeiro na região Nordeste e seu controle. Fortaleza: Embrapa Agroindústria Tropical, 2003. 11p. (Comunicado Técnico, 86).

YAMASHIRO, T.; LANDGRAFF, J.H. Maracujáaçu (Passiflora alata Ait), porta-enxerto resistente à fusariose do maracujazeiro (Passiflora edulis $\mathrm{f}$. flavicarpa Deg.). In: CONGRESSO BRASILEIRO DE FRUTICUlTURA, 5., Pelotas, 1979. Anais... Pelotas-RS: Sociedade Brasileira de Fruticultura, 1979. p.918-921.

ZAR, J.H. More on dichotomus variables. In: ZAR, J.H. Biostatistical analyis. New Jersey: PrenticeHall, 1999. p.516-570. 